\title{
Aortic Surgery Symposium 2012 discussions-Panel 4 (sessions VII and VII): Descending thoracic aorta, thoracaobadominal aorta, and dissection
}

\author{
Moderator: Steven L. Lansman, MD, PhD, Westchester Medical Center, Valhalla, NY. \\ Panelists: Wilson Y. Szeto, MD, Hospital of the University of Pennsylvania, Philadelphia, Pa; Giampiero \\ Esposito, MD, Department of Cardiovascular Disease, Cliniche Humanitas, Gavazzeni, Bergamo, Italy; Niels \\ Rahe-Meyer, MD, Clinic for Anesthesiology and Intensive Care Medicine, Franziskus Hospital Bielefeld, Ger- \\ many; Ourania Preventza, MD, Division of Cardiothoracic Surgery, Department of Surgery, Baylor College of \\ Medicine, Texas Heart Institute at St. Luke's Episcopal Hospital, Houston, Texas; Eric E. Roselli, MD, Cleve- \\ land Clinic, Cleveland, Ohio; G. Chad Hughes, MD, Duke University, Durham, NC; Toru Kuratani, MD, \\ Cardiovascular Surgery, Osaka University Graduate School of Medicine, Osaka, Japan; Santi Trimarchi, MD, \\ Thoracic Aortic Research Center, IRCCS Policlinico San Donato, Milano, Italy; Marco Di Eusanio, MD, \\ Departments of Cardiac Surgery, S. Orsola-Malpihgi Hospital, Bologna, Italy.
}

\section{Discussion}

Dr Lansman. Let's just start off the discussion with type A dissection. You get a call for an acute type A dissection at your institution. Where do they go? Are they admitted to the intensive care unit (ICU), to the emergency room (ER), or to the operating room (OR)?

Dr Szeto. As you mentioned earlier, our paradigm has been a direct trip with a type A aortic dissection to the OR.

Dr Lansman. To the OR?

Dr Szeto. Correct. And with the changing paradigm of adjunct endovascular techniques, we would send some selected patients to the hybrid OR, depending on the clinical scenario.

Dr Lansman. As I mentioned in my talk, we adopted that strategy early on, and I must say I think it has made the difference in at least $10 \%$ of our patients, whom I don't think would have made it from the ER or the ICU or a standard workup to the OR. So our protocol, just to amplify on that, is they are admitted to the OR. The entire team is called in, the patient gets an echo on the table, and if it is not a dissection, everyone goes home; but everybody is there if it is an acute type A dissection.

Dr Esposito. They go to the OR with a transesophageal echo.

Dr Rahe-Meyer. We do the same.

Dr Roselli. Our patients are assessed in the ICU—we confirm the diagnosis there-but we have an OR that is essentially always mobilized. It is pretty quick.

Dr Hughes. It's on a case-by-case basis. The majority of our patients are transferred in rather than coming in to our ER, but certainly if somebody presents to our ER with a dissection that is a surgical candidate, we go straight to the OR. If it is an 85-year-old, we are going to want to see him first before we take

Disclosures: Authors have nothing to disclose with regard to commercial support. Read at The American Association for Thoracic Surgery Aortic Symposium, New York, New York, April 26-27, 2012.

Address for reprints: Eva B. Griepp, MD, Department of Cardiothoracic Surgery, Mount Sinai School of Medicine, New York, NY 10029 (E-mail: ebgriepp@aol. com).

J Thorac Cardiovasc Surg 2013;145:S222-8

$0022-5223 / \$ 36.00$

Copyright (c) 2013 by The American Association for Thoracic Surgery

http://dx.doi.org/10.1016/j.jtcvs.2012.11.083 him to the OR, but if it is a young patient, we take him straight to the OR.

Dr Lansman. Let me just move on. So we have got them admitted. Are there any patients you are not going to take to the operating room? You are just going to say, "I'm sorry. This is beyond our limit." Do you have any limits?

Dr Preventza. Actually, it is very rare we turn down patients for surgery. Most of the time, if the patients come to us, we do operate. There are cases-if somebody has had prior cardiac surgery and comes to us with a type A dissection-when definitely we wouldn't rush to the OR. We would proceed a little more semi-electively. If we have the 85 -year-old with a neurologic injury and a cerebrovascular accident, that is when, most of the time, we discuss the situation with family and we see what their wishes are. But the reality is that it's very rare that we turn patients down.

Dr Lansman. Dr Di Eusanio, we know what your thoughts are on coma, but what about age?

Dr Di Eusanio. Age, I think, is no contraindication to operating for an acute type A dissection. There is no age limit. I think if the patient is in good condition, presenting well with good hemodynamics and no renal failure, I think that surgical therapy can be associated with better survival than medical therapy. So I don't think that we should give a number, like 90 years, 85 years, or 95 years. I think it is a biologic matter.

Dr Lansman. We would certainly agree with that. Wilson, any age indications or contraindications?

Dr Szeto. Nimesh Desai recently looked at our data looking at exactly that-risk factors, and you alluded to that abstract earlier. There are certainly markers of high-risk patients: patients who are elderly, in their late 80s; patients with malperfusion; patients with rupture, etc. We don't, per se, absolutely say no, but it certainly does sound a word of caution for us in terms of proceeding with surgery. As Dr Preventza said, with redos oftentimes we proceed in more of a delayed fashion. In a patient with previous coronary bypass grafting, we would perhaps need more information about the status of their coronary anatomy. We have also been very reluctant to operate on patients with severe or devastating neurologic injury. That's the one group that-at least in our hands-we have been very reluctant to offer emergency surgery. 
Dr Lansman. Well, I'm glad you mentioned visceral malperfusion. Eric, are you taking people straight to the OR with visceral malperfusion?

Dr Roselli. Yes, we do. We would take them to the hybrid OR right away and, not only mobilize our standard team, but we also let the vascular surgeon on call know in case we need assistance with possibly more complicated peripheral stenting afterward.

With regard to brain injury—comatose patients—we will get a portable computed axial tomographic scan in the ICU and, if we see that the brain looks okay, we take those patients to the OR as well. And looking at the data you showed, you saved a lot of those comatose patients. So unless we have some sort of objective evidence that their brain is gone, we try and save those folks, too.

Dr Lansman. So, getting back to the viscera, let's say you get a call from one of your referring hospitals. They have been watching someone for 2 days; they aren't sure what is going on. Now they realize that the patient has really had an acute abdomen for a day. He is being transferred over; his $\mathrm{pH}$ is 7.1. What would you do with that patient?

Dr Roselli. I think if that patient is still alive 2 days later and talking to you, the bowel may be ischemic and not dead. So if he is young, we will take him, and we will open his belly after we open his chest, and take a look and shoot an angiogram and revascularize things.

Dr Lansman. Are you still in the audience, Dr Deeb? Do you want to comment about that? How would you handle that?

Dr G. Michael Deeb (Ann Arbor, Mich). If we think the patient has end-organ damage, we will take him to the OR to a hybrid suite. Our main goal is to revascularize that patient and then to stabilize him and make sure he doesn't have dead bowel before we open his chest and try to prevent tamponade. If he has no evidence of tamponade and he has evidence of dead bowel, he is going to die of dead bowel. There are reasons for taking patients to the OR, and we take them to the OR to try to prevent them from dying. And there are different causes for patients dying. Not all patients die from acute tamponade and rupture of their ascending aorta. And so we try to list the complications in their order of severity, and we try to attack the most severe first. So the particular patient who has evidence of dead bowel, we would revascularize without opening his chest, stabilize him, make sure his bowel is not deador get rid of the dead bowel-prior to taking him to the OR if he wasn't tamponading.

Obviously, if we have a patient who comes in to our institution that has both problems - tamponade and evidence of ischemiathat is a patient that you have to treat right away for both problems. We think that is an ideal patient for a frozen elephant trunk and then treatment with the standard combined surgery as the group at Penn and Cleveland Clinic do. But if a patient has evidence of dead bowel, we wouldn't proceed with opening the chest. We would stabilize him. That's just the way we do it. I'm not saying it is right or wrong; it is just different.

Dr Preventza. We had a few patients like that, and the first thing that we did was open the abdomen, especially if there was a question about dead bowel. I think that if the bowel is dead or if the patient is comatose, the mortality is very high, and it can almost be futile to try to do anything else. If the bowel is ischemic but is not what we would call dead bowel, then we try to revascularize after that.
Dr Lansman. Visceral malperfusion. Any other opinions on the panel?

Dr Szeto. As technology improves - and we are going to find this out-there may be a small, selected group of patients whom we should be treating with endografting for type A dissection. Maybe these are patients to treat with an endovascular approach for the ascending aorta. As you know, we have done a few patients at Penn using endovascular techniques for correction of malperfusion in the abdomen. In the near horizon, with technologic improvements, stenting type A aortic dissections in this small, highly selected group of patients may be of some value.

Dr Lansman. I always wondered about that. It seems to me, most of the tears are very close to the sinotubular junction, sometimes into the coronary ostia. How are you going to get a landing zone that is going to exclude the tear?

Dr Szeto. Well, I think you have to be careful. The patients have to be selected carefully. These are patients in dire condition. It is an option if, to your best knowledge, you can tell based on a computed tomographic (CT) scan where the tear site is. Oftentimes, as you know, that is difficult, and you may have to do that in conjunction with an intraoperative transesophageal echocardiography. These are small numbers of selected patients. But there may be some value in this technique for the future, if you know the tear is somewhere in the ascending aorta proper, and the patient is acidotic and you just don't think you can get him through an open operation. This may be a method of delaying the insult —of getting the patient through and then having options down the road.

Dr Roselli. Steve, when Michael Moon was a fellow at our institution, he did a retrospective analysis of a bunch of CT scans on acute type A dissection patients with that question in mind, and found that about two thirds of patients actually had about a centimeter between the tear and their coronaries, which would allow for potential coverage of the entry tear.

Dr Lansman. I am not sure when you look right at it. Well, perhaps a centimeter. Is that what you call a good landing zone these days?

Dr Roselli. I have treated 2 such cases and it has worked, but it has been in undoubtedly dire situations.

Dr Hughes. Well, with regard to malperfusion in the gut, the only thing that I would add is you should obviously look at your CT scans carefully and figure out the etiology of the malperfusion. If it is static malperfusion-when the celiac and superior mesenteric artery are clearly dissected and thrombosed-even if you fix the type A dissection, you are not going to restore flow in that scenario, and that's a very highly lethal problem. And that's the situation in which Dr Deeb and Patel's complication-specific approach is probably the best option, even though it's not going to be a great result. You might want to stent the descending aorta and go after those branch vessels, and then, later, fix the type $\mathrm{A}$ if you can get flow back to the gut. Because if you fix the type A dissection, it's not going to help the visceral malperfusion.

Dr Lansman. I see Dr Bachet at the microphone. We shared a panel with Dr Cooley about 20 years ago and the discussion was about type A dissection. Somebody asked a question from the audience: If they come in at 3 in the morning, can you wait until 8 in the morning to take them to the OR? I'm embarrassed to say I thought you could. We no longer do that. Dr Bachet said we were immoral. I didn't realize I was dealing with a French philosopher. 
Dr Jean E. Bachet (Abu Dhabi, United Arab Emirates). I still think that waiting for an acute dissection is immoral, indeed, despite my old age. I have 2 questions and comments -1 for Dr Preventza and 1 for Dr Esposito. I will start with Dr Preventza.

I am quite surprised that one of the most important departments of aortic surgery in the world has discovered cannulation of the innominate artery in the 21 st century. We were doing this for the past 30 years absolutely liberally, and I am stupid because I didn't publish it. So I have 3 comments.

The first comment: The data you give about the complication, morbidity, etc, have nothing to do with cannulation. You should have exactly the same results whatever cannulation you use. Second, I have 2 comments about the technique. Forget the Dacron graft; it is completely useless. All innominate arteries are like my thumb. You can put an aortic cannula in them directly. It is simpler-two purse-string sutures and that is it. The last comment applies not only to your presentation, but to all the videos and slides we have seen in these 2 days about arch surgery. I see people fighting constantly with the innominate vein. Divide it, cut it; nothing happens, and you have the whole space to do the arch surgery. That is what I wanted to say about innominate artery cannulation. But it is an old technique; it is not a new technique. For me, it was so natural to use it that I was really surprised to see it presented as an innovation.

My second comment goes to Dr Esposito. A few months ago in Bologna, at the aortic symposium of Dr Di Bartolomeo, I gave a lecture comparing the evolution of aortic surgery with the evolution of the architecture and plastic arts in Italy between the renaissance and classicism to the baroque style, and your presentation exactly illustrates that. We are entering a completely baroque, not to say rococo, era.

What I mean is that I don't really understand the rationale-and I would like you to explain it to me-of your technique. Why is it advantageous compared with conventional arch surgery with an elephant trunk and, 2 months later, the same thing you do in your patients, a normal, completely conventional replacement of the thoracoabdominal aorta? Because, first of all, when you say that debranching is easy, I don't know. Ten anastomoses that can bleed, meters of Dacron that can thrombose, etc. And in the belly, it is heavy surgery. It takes, I suppose, 2 or 3 hours to open the abdomen, to put in the graft, to sew all those Dacron grafts onto the renal arteries, etc. Do you think that this is really easier and simpler for the patient and for the surgeons than thoracoabdominal surgery?

Dr Esposito. Thank you for your question, Jean. I was afraid that you weren't here to ask some questions of me. So I am really happy to answer them.

Just saying it is easier means, of course, the whole evolutionthinking of it in terms of what to do, whether classic therapy or the new type of repair. In my experience of 6 years, what I say is that for dissection or for a degenerative aneurysm, the treatment of arch surgery in this way-with 2 simple anastomoses and without the arch, without the frozen elephant trunk, and going to do a very anatomic correction of the bovine trunklike replacement of the carotid artery or innominate artery-looks very good. This is my personal opinion. But I see that there are a lot of people that share my idea, of course, with different methods and so on.
Speaking about the thoracoabdominal, of course I started vascular surgery with Prof Pierangeli many years ago, looking at him doing operations. In everybody's hands, and even for people with a specialization in this type of surgery, it is a very hard operation. And also the debranching in the open abdomen is a very long operation. So we need to decrease it. But looking at the literature of doing it from the iliac artery, I came to think that this type of approach is wrong because the iliac artery is not good. But from the abdominal aorta, it is much easier to arrange debranching to correct a very huge aorta subsequently. This is my opinion, of course, and maybe there is somebody more experienced than I am that can say what is wrong or what is right.

Dr Lansman. I know Eric has to leave a little early, but I have to get my question in before he leaves. Perhaps you said it and I missed it. Is there anyone in whom you are not going to do a fixed elephant trunk on with an acute type A? Is it selective? How do you choose?

Dr Roselli. Basically, it is for all the type 1 dissections that I have run into. I initially thought I would be selective. The first couple of patients I saw had a tear in the arch; another patient had two tears- 1 in the descending aorta and 1 proximally - then the third patient's arch was $>4 \mathrm{~cm}$. After doing 3 or 4 of these in patients who had what seemed like a good indication, I realized that it was pretty easy, and so I have applied it to all the type 1 dissections. Certainly, I think we ought to study it, though.

Dr Lansman. My talk was on octogenarians. In an 82-year-old woman with a type A, are you going to do a fixed elephant trunk?

Dr Roselli. I have an 87-year-old who was fishing on his boat, and he's doing fine, and I don't have to deal with his upper descending aorta now.

Dr Martin Czerny (Berne, Switzerland). I have a question for Dr Trimarchi. I liked his idea, and when the first publication on this issue came out, I applied this concept to our patient group. The main problem for me was to define which false lumen is really partially thrombosed. So how do you differentiate between low flow and real partial thrombosis, because I think there is a major difference. Actually, what came out in our analysis, which we published recently, was that the thrombosis status of the false lumen was not an independent predictor in our series; the only independent predictor with us was patency or closure of the primary entry tear. So, in other words, I think it makes a substantial difference if you have retrograde perfusion of the false lumen, which may, of course, result in partial thrombosis because it is a blind sac, but this flow is not highly pressurized. However, if flow is antegrade, then it makes a huge difference, because then you have this blind sac phenomenon.

So the first question would be: What is your exact definition of partial false lumen thrombosis? I think that in the future, we will be able to identify the patients with functional imaging. So what we do now: Do we subject each and every patient with an acute type B dissection to cine magnetic resonance angiography? Do we try to quantify the number of communications between lumina, the volumes of both lumina, as well as a noninvasive measurement of blood pressure in both lumina? I think somewhere there lies the answer.

Dr Trimarchi. It is a very complicated, tough question. We have had many thoughts about this. About how we define the presence of thrombus in the false lumen, we thought and thought, and 
then the answer came out as a really easy thing. We checked into the venous phase of the CT scan. If we saw in the same section both contrast and thrombus, we called this partial lumen thrombosis. There are some papers - in particular, the second paper from the Sueoshi group - who report saccular formation of the false lumen. What I think is that we are in the presence of many variables that we are trying to evaluate to understand which patients will have such important aortic growth that they will develop an aneurysm. I think that, up to now, we don't have the complete answer to this. We are probably evaluating several different conditions in the imaging of these patients.

We observed, for example, that the number of entry tears in another paper is strictly associated with increasing aortic growth rates. We ourselves have observed the most dramatic growth when we have only 1 entry tear that has been detected, and the best results in terms of reduced aortic growth rate when we have 4 entry tears. So we do not have saccular formation and low flow. And another thing, as you published recently, is the inner versus the outer curvature. There are other variables that we are evaluating, such as spiral and straight on the same patients, the presence of atherosclerosis, arch diameter, and the presence and number of additional vessels that are intersected by the dissection. So there is no one answer. But I think that in the next 2 or 3 years, we will know much more about those patients who are at increased risk for aortic dilation.

Dr Di Eusanio. I would just like to step back to type A dissection and frozen elephant trunks. In Bologna, we have done, thus far, more than 120 cases, and only roughly $10 \%$ in patients with type A dissection. I believe that patient selection is crucial in these patients because the frozen elephant trunk increases significantly the duration of extracorporeal circulation and circulatory arrest. So a very old patient would be likely to have a less satisfactory outcome.

I also think that there is a nice indication, an anatomic indication, for the frozen elephant trunk in type A dissection. That would be a type A dissection with a very distal entry tear, let's say in the neighborhood of the origin of the left subclavian artery. These patients would otherwise require a complete arch replacement with a very deep distal anastomosis, which may be very demanding and potentially at risk for bleeding and rupture. So with a frozen elephant trunk, the procedure may be greatly facilitated by performing the distal anastomosis at the more proximal level-let's say proximal to the left subclavian artery-leaving the stent graft to cover the distal entry tear and take care of the distal repair. So I think that is a nice anatomic indication for the frozen elephant trunk in type A dissection.

Dr Jason Sperling (Ridgewood, NJ). First, a comment on the paper from Houston regarding your technique of innominate artery cannulation. I noticed you had about a $4 \%$ stroke in your seriesnot a huge number-but I was wondering whether some of that stroke incidence was from unnecessary instrumentation of the left common carotid artery. We have a similar technique at our place. We sew an 8-mm graft onto the innominate artery; my apologies to Dr Bachet. We only control the proximal innominate, and we snare the left common carotid and cool to $28^{\circ} \mathrm{C}$. We keep the radial blood pressure at $80 \mathrm{~mm} \mathrm{Hg}$, and manipulate our flows based on the forebrain oxygen saturations as seen on cerebral oximetry. We have had 0 stroke in, now, about 50 or 60 arch cases. So I just wonder if the instrumentation of the carotid artery is necessary, because I've never had to instrument the carotid artery to perfuse it directly using this technique.

And my question was for the doctor from Hannover regarding the fibrinogen injection. Like Factor VIII, we know Factor VII is really good at stopping bleeding, but the cost is in strokes and thrombotic events - thrombosed grafts. I was wondering if you could comment whether any of those patients have had any thrombotic complications.

Dr Preventza. First of all, to Dr Bachet, I agree with the fact that Texas Heart is a major aortic surgery center, and I know that Dr Coselli has used innominate artery cannulation before in the past for quite a few years. But for the past few years, we have used right axillary cannulation as a routine. Since June, there have been 68 consecutive patients with innominate artery cannulation. The reason that we did that is because we thought that perhaps we could save some time and don't always need to do an unnecessary incision. With regard to the innominate vein, we have never really had a problem, so we haven't really felt the need to divide it.

With regard to the comment about stroke, we had 3 patients with stroke. One had extensive stroke and the 2 others actually had partial recovery. When we did the analysis for neurologic events, the $P$ value for age and antegrade cerebral perfusion (ACP) duration was significant. For 2 patients - including the 1 patient who had extensive stroke-the ACP time was prolonged. The third women with a partial-deficit stroke was 86 years old. So we didn't really think that any of these 3 patients had a problem in which instrumentation contributed to the stroke. We thought that the prolonged ACP time for the 2 patients as well as the advanced age of the 1 elderly woman contributed to the stroke. In most of these patients, we did a distal anastomosis open or a complete arch, and they required coronary artery bypass, thoracic endovascular aortic repair (TEVAR), or a mitral valve, as well; they were pretty complicated cases.

Dr Lansman. I am not sure I would like a thrombus hanging on the side of my carotid indefinitely when you oversew that little stump of graft. Is there any issue long term? Have you ever heard of anything?

Dr Sperling. Because we do surveillance on all these patients after their surgeries, you can actually see that stump on every single computed axial tomographic scan, and it opacifies with contrast, at least for us. So I don't think there is any necrosis. It is an 8-mm graft that is quite big; there's probably just some swirling flow in there.

Dr Ian Nixon (Melbourne, Australia). The video demonstrates a technique that we evolved 5 years ago of balloon rupture of the dissection membrane. We do it on acute type A and acute type B patients - on all-comers. It's safe, reproducible, and simple, and obliterates the false lumen entirely and totally eliminates malperfusion without further procedures. We think it is a remarkably simple and safe thing to do. It looks radical and dramatic, but it works surprisingly well.

Dr Lansman. And how far down does this go?

Dr Nixon. Throughout the dissection. We would go to the aortic bifurcation, if needed. So we totally obliterate the false lumen wherever it finishes.

Dr Lansman. Can you show the slide, please?

Dr Nixon. You can see that this technique has totally obliterated the false lumen in the thoracic aorta and, in all but 1 patient, in the 
abdominal aorta. Of note, there has been no increase in the size of the aorta for a follow-up period of as long as 5 years. So having insertion of a bare stent and disruption of the intimal flap does not lead to further dilation of the aorta. It seems to heal exactly the same after we have disrupted it for up to a follow-up of 5 years. We do have access to branches that come off the false lumen by wire, but there have been no instances when we have needed to go back and stent or stent-graft those branches. They are already perfused with disruption of the flap. The majority of patients in whom we have done this have had a dissection complicated by malperfusion. So the technique has been remarkably successful and remarkably simple.

Dr Hughes. So why not do it in every type B dissection? Or do you do that already?

Dr Nixon. We do.

Dr Hughes. Everyone?

Dr Nixon. We do, and in every type A, as well. Once we have done the proximal surgical correction, on the table we do this exact procedure for type A and for all type Bs.

Dr Hughes On the type A, how far proximally do you go then with your repair? Just to the subclavian?

Dr Nixon. Yes, just to the subclavian.

Dr Hughes. You are not doing a full arch, so I guess you have some residual short-segment dissections potentially in between your ascending and-

Dr Nixon. Well, it depends whether you have a reentry in the branch vessels or whether the tear goes through the arch. If the reentry occurs in the branch vessels, then we would stent those to block the reentry. It doesn't entirely address the problem of residual arch dissection, and we have some ideas on how to do that, too.

Dr Hughes. Do you stent the arch vessels through the open arch or do you it at the time when you put-

Dr Nixon. We would come back and do that at a second sitting.

Dr Hughes. When do you that part in the type As?

Dr Nixon. Before the patients go home. We reestablish flow in every vessel, and we know that before they leave the OR. So we have had no malperfusion, we have had no mesenteric ischemia, we have had no renal failure. And it is a quick and reliable 1-step procedure that corrects the whole dissection anatomically, and there is no risk of further complications from false lumen enlargement of the distal aorta, whether it be thoracic or abdominal. We produce an anatomically corrected aorta throughout.

Dr Trimarchi. I think it is the extension of the concept that came out of the Study of Thoracic Aortic Type B Dissection Using Endoluminal Repair (STABLE) trial with the Provisional Extension to Induce Complete Attachment (PETTICOAT) condition approach for Bs, but they applied this technique only for those type $\mathrm{B}$ patients who had a complication. The results seem to be very good in the short term and the mid term. It looks very good.

Dr Nixon. That is accurate. This is an evolution from the STABLE trial that we designate as stabilized. So this is a further derivative from the STABLE group. The STABLE group ran up to about 5 years ago, and we have used this technique exclusively since then in the acute patients with a normal-size aorta.

Dr Rahe-Meyer. I still have to answer the question of a colleague about the safety issues-especially thromboembolic events-while using fibrinogen concentrate. The simple answer would be there were no thromboembolic events in the fibrinogen group, whereas there were 2 or 3 in the placebo group with more allogeneic blood products. Taking into consideration that we only had 61 patients treated, of course, it is really necessary to have more sound safety data.

But I can tell you something more about my experience with that product. In some parts of Europe, we have been using it for more than 25 years now for perioperative bleeding, and it seems really to be incredibly safe. The question is why. I think there is a big difference between coagulation factors that influence the thrombotic potential-prothrombotic or thrombin-building factors-which you find in NovoSeven or in prothrombin complex concentrates, on the one hand, and passive substrates like fibrinogen concentrate or factor XIII concentrate, on the other hand, which don't influence the balance between thrombosis and antithrombosis. This may be the reason why I have not seen and I have not heard of any real thromboembolic events that could be attributed to the administration of fibrinogen concentrate. In contrast, I have heard of many complications of factor VII and PCC, and I have seen some myself, and I am pretty cautious about administering these prothrombotic factor concentrates.

Dr Kuratani. During acute type B aortic dissection in Japan, we almost never use expansion, even if it is a malperfusion patient. Usually, entry tear closure after malperfusion injury is not good. I have 1 question about the long-term results: Do you have some patients with a neointimal tear or some other problem on the distal side?

Dr Nixon. They all have neointimal tears, because we disrupt the whole of the dissection starting at the bottom end of the covered stent graft. So we are intentionally producing the intimal tear. We haven't had intimal tears from the proximal hook fixation of the Cook TX2 grafts that we have used proximally; that hasn't been a problem. What we do is to rupture from the lower third or so of the covered stent graft, which we take down to a segment of aorta that is normal in total diameter and then start to disrupt the dissection flap at that point.

It is true that the stabilized group that we did before had very good results with no malperfusion, but that doesn't totally address the growth of the false aneurysm, and it doesn't totally thrombose the false aneurysm. We have $90 \%$ thrombosis in the thoracic aorta using STABLE, but we still have about a $40 \%$ incidence of patent false lumen in the abdominal aorta. And so this technique evolved to address that.

And it also simplifies treatment, because doing it acutely with a 1-step technique when the aorta is a normal size, we found that we have no need to reintervene in anything. They don't have a false lumen; they don't have malperfusion. They heal and they remain stable. The aorta doesn't grow. So we have a group of patients who have, apart from their stent grafts, ostensibly normal CT scans of their aorta. And this includes both type A and type B patients. So it addresses the long-term evolution of the false aneurysm and late complications of rupture, plus it addresses the malperfusion issues.

Dr Michael Raabe (Winnipeg, Canada). I was just interested in the panel's management of a patient that we see not infrequently - a patient with an acute type A dissection that goes all the way down to the iliac arteries, and the CT scan shows that the celiac artery comes off the true lumen, the superior 
mesenteric artery off the false lumen, one of the kidneys comes off the true lumen, and the other one off the false lumen. The CT radiologist tells you, well, one of the kidneys is enhancing with contrast and the other one isn't. So we do what most of the panel earlier said, which is we deal with the original dissection and get a live patient out of the OR. But I am interested in what do you do with the visceral scenario that I just outlined, and what is the timing of that intervention, especially given what we have heard just recently about all the negative effects of a patent false lumen in the long term?

Dr Szeto. A very good question. As you know, our center, along with Eric, has been one of the proponents of a frozen elephant trunk at the time of the first operation. And what we learned early on, painfully, is that patients, just as you have described, may not benefit from that technique-patients with perfusion of the different mesenteric arteries off different lumens. We have learned, from our experience, that those are the patients we probably should leave alone and not do a frozen elephant trunk and just do the standard proximal repair.

In terms of timing, every patient is different, obviously, but again, we get them out of the OR, get them reperfused, resuscitated, and we watch them closely. If there is ever any sign of abdominal deterioration, peritonitis, renal failure, that is when we would have a very low threshold to go back to the OR either for an open or an endovascular intervention, depending on the pathology, malperfusion, rupture, etc.

Dr Lansman. One of the hot topics for the first 10 aortic symposia was whether we should resect the tear for a type A dissection and whether you should do an open distal anastomosis, and each time it would be debated. Very quickly: Do you do an open distal anastomosis and do you try and resect the tear?

Dr Preventza. Yes, we always do an open distal anastomosis for a type 1 dissection.

Dr Di Eusanio. Yes, absolutely.

Dr Trimarchi. All cases, $100 \%$ of patients.

Dr Kuratani. No, we usually use a frozen elephant trunk.

Dr Hughes. We do an open distal anastomosis, but if the tear was in the proximal descending thoracic aorta, I wouldn't do a total arch in an acute type A dissection; I would just leave it alone. It's not going to kill them in the short term.

Dr Lansman. I agree with that. You don't know where the tear is, however, if you don't do the open anastomosis.

Dr Hughes. We do an open distal anastomosis $100 \%$ of the time.

Dr Esposito. What we do is an open distal anastomosis, of course, and then we eventually do debranching of the vessel if we have to do a TEVAR.

Dr Szeto. An open distal anastomosis, yes.

Dr Lansman. Is there anybody not doing an open distal anastomosis in the audience? Just 2 left; it used to be about a third. I guess slow progress.

Dr Preventza, an uncomplicated type B dissection gets admitted. How do you treat that patient in Texas?

Dr Preventza. Most of the time, if it is an uncomplicated type B, first of all, we evaluate the CT scan based on Sundt's paper. If the false lumen is $>22 \mathrm{~mm}$, there is a high incidence of aneurysm and death. Therefore, we tend-if the false lumen is $>22 \mathrm{~mm}$ - to stent. But we have to look carefully at the CT scan and really see if this patient is going to benefit from early TEVAR. Other times, we just do antihypertensive therapy.

Dr Di Eusanio. Uncomplicated type B: medical therapy.

Dr Lansman. And what are your indications for surgery?

Dr Di Eusanio. For surgery or for TEVAR?

Dr Lansman. Intervention.

Dr Di Eusanio. Complications, of course, are the indications for intervention. So, refractory pain, malperfusion, increasing size and evolution of the aortic lesion on the CT scan-the classic criteria.

Dr Trimarchi. We initially treat with a medical approach, but, of course, we pay much more attention to imaging now than before to determine if we have some predictor that could indicate a need for early treatment.

Dr Kuratani. I showed in my presentation that we have some anatomic indication for the uncomplicated type B dissection in our data: $>40 \mathrm{~mm}$ of aortic diameter at the onset. And, for the uncomplicated case, we usually try the TEVAR operation.

Dr Hughes. An uncomplicated type B dissection would still be managed medically. For the high-risk uncomplicated that I referred to-a patient with a 4-cm/22-mm false lumen-I don't know that you need to do him immediately. I think Thor's data say you have as long as 9 months to do those folks. I would be interested to hear what the panel would say. If you are going to treat those people, do you treat them in the acute phase or do you wait, get a CT after a month, see how it looks, and treat them then? I think we have tended to do that more. If it is really otherwise uncomplicated, we might just see what the 1-month CT looks like and decide about TEVAR at that time, because I don't think it makes a difference to the result you get if you wait a month.

Dr Lansman. Is there a high-risk group that you are watching carefully?

Dr Hughes. All the criteria you know-a 4-cm patent false lumen, a 22-mm false lumen, an intramural hematoma (IMH) patient who develops a new penetrating ulcer in the proximal descending thoracic aorta, refractory pain or hypertension - those you have to treat. I think refractory hypertension is a little bit subjective; I'm not sure how you define that.

Dr Lansman. I may have missed it in your talk, but a false lumen $>4 \mathrm{~cm}$ and a patent false lumen-are you just bringing those patients back and doing an intervention? Or are you watching them?

Dr Hughes. If somebody came in and they had a 4-cm patent false lumen and otherwise were completely uncomplicated, I wouldn't actually do them right away. I probably would see how their 1-month CT scan looks, but I would tell them that there is some chance they're going to need-

Dr Lansman. You just watch them carefully?

Dr Hughes. Yes

Dr Esposito. I underline the importance of the $22 \mathrm{~mm}$ for the false lumen with false lumen thrombosis, which is very important for us. So, in that case, what we do is debranching of the left subclavian artery to the carotid, and then we put in an endoprosthesis.

Dr Szeto. A similar approach as mentioned by Drs Hughes and Esposito, and some of the members of the panel. The majority of time we treat uncomplicated type Bs medically, but there are some anatomically high-risk patients, as you mentioned, that we treat aggressively with TEVAR. Maybe not right away, as Chad 
mentioned. In Philadelphia, and I am sure here, as well, not a small number of patients have compliance issues. So if I know a guy is not going to come back, I am more likely to treat him that same admission.

Dr Lansman. A type A IMH comes in.

Dr Szeto. In general, unless there is a clinical scenario that would preclude us from operating, we are fairly aggressive with operating on type A IMHs. I know there are a lot of Japanese data that suggest that there is a small set of patients that you might be able to manage medically and watch, but at least in our seriesin a small handful of patients - the outcome has not been good, meaning they rupture. So we have been fairly aggressive unless there are medical reasons-prohibitive reasons-not to operate on those patients.

Dr Lansman. All right. You may know that in Dr Safi's group, with a type $\mathrm{A} I \mathrm{IMH}$, if the aorta is $<5 \mathrm{~cm}$ in diameter and the hematoma is $<1 \mathrm{~cm}$ thick, he operates on them, but he watches them initially. They operate on them about day 7; they think that it is an easier operation. We are considering it, but Dr Spielvogel won't let me do it, so we haven't done it yet.

Dr Esposito. It depends on the age and the comorbidities. If it is a young patient, I really am aggressive. Otherwise, if it's an 80year-old patient, we take control and we see what happens.

Dr Hughes. Pretty much the same. It seems these patients tend to be more elderly in general; there are a lot of older patients. For the 85-year-old with a lot of comorbidities, certainly with $<$ a 5 -cm aorta and no pericardial effusion, we treat that patient medically. But the young patient is going to get surgery.

Dr Lansman. Do we have an opinion from the Far East?

Dr Kuratani. Usually, we wait on the operation if it is an IMH. But it depends on the thickness of this IMH diameter. Usually, we check every month by CT scan. So careful follow-up of the patient is very important.

Dr Lansman. It is really remarkable the difference in the literature from the East and from the West in the incidence and the malignancy. 